\section{Commentary: When you hear hoofbeats think horses - but don't forget the zebras!}

\author{
Minoo N. Kavarana, MD
}

Congenital coronary artery fistulas (CCAF) are rare coronary artery anomalies that develop when the obliteration of intramyocardial sinusoids fails, resulting in persistent connections between the coronary arteries and a cardiac chamber. ${ }^{1}$ CCAFs commonly originate from the right coronary artery and drain into right-sided cardiac chambers. ${ }^{2}$ The first surgical ligation was performed in 1947 by Bjork in a patient misdiagnosed with a patent ductus arteriosus (PDA).

Sakakibara classified CCAFs into type A fistulas with side-to-side connections, dilated proximal coronary artery, and normal distal segments and type B end-to-side fistulas with diffusely dilated coronary arteries. ${ }^{4}$

Although most patients are asymptomatic or present later in childhood with progressive congestive heart failure, occasionally neonates with large fistulas may present acutely with hypotension and myocardial ischemia from coronary artery steal. ${ }^{5}$ The differential diagnosis includes PDA or aortopulmonary window detected on transthoracic echocardiography. Precise definition and localization may be performed by computed tomography angiography and coronary angiography and is critical for planning the appropriate surgical or catheter-based approach.

The 2 major potential complications from either surgical ligation or catheter-based coil occlusion are myocardial ischemia from coronary obstruction or distortion and residual fistula from in-complete ligation.

\footnotetext{
From the Section of Pediatric Cardiothoracic Surgery, Medical University of South Carolina, Charleston, SC.

Disclosures: The author reported no conflicts of interest.

The Journal policy requires editors and reviewers to disclose conflicts of interest and to decline handling or reviewing manuscripts for which they may have a conflict of interest. The editors and reviewers of this article have no conflicts of interest.

Received for publication Aug 8, 2020; revisions received Aug 8, 2020; accepted for publication Aug 13, 2020; available ahead of print Aug 15, 2020.

Address for reprints: Minoo N. Kavarana, MD, FACS, Pediatric Heart Transplantation and Mechanical Support, Section of Pediatric Cardiothoracic Surgery, 10 McClennon Banks Drive, SJCH 2190/ MSC 918, Charleston, SC 29425 (E-mail: kavarana@musc.edu).

JTCVS Techniques 2020;3:299

2666-2507

Copyright (C) 2020 The Authors. Published by Elsevier Inc. on behalf of The American Association for Thoracic Surgery. This is an open access article under the CC BY-NCND license (http://creativecommons.org/licenses/by-nc-nd/4.0/).

https://doi.org/10.1016/j.xjtc.2020.08.029
}

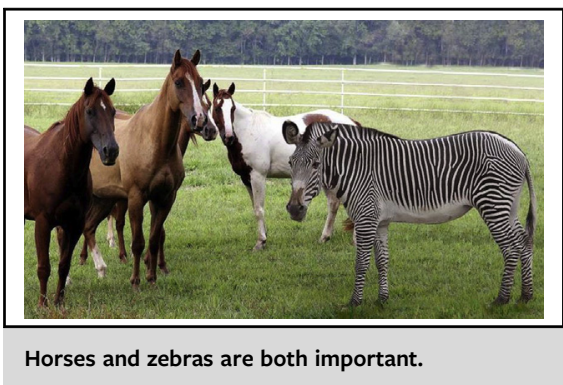

CENTRAL MESSAGE

Congenital coronary artery fistulas rarely present in the neonatal period. A novel hybrid approach is described that provides precise identification and aids meticulous surgical ligation.

The authors describe a novel hybrid approach that involves precise localization by selective coronary angiography, followed by placement of a wire across the fistula before surgical ligation. ${ }^{6}$ The retained wire facilitates precise identification and repair of the fistula from within the coronary fistula and the chamber into which it drains. In addition, the value of performing immediate postrepair completion angiography is emphasized by the fact that despite precise wire localization, a residual fistula persisted, which was identified and completely ligated using the epicardial approach.

Although CCAFs are rare, they should be considered in the differential diagnosis either in isolation or during repair of concomitant congenital heart defects in patients who present with hypotension and myocardial ischemia. This report highlights yet another application and utility of the hybrid cardiothoracic surgery operating room in the management of complex congenital heart defects.

\section{References}

1. Rittenhouse EA, Doty DB, Ehrenhaft JL. Congenital coronary artery-cardiac chamber fistula: review of operative management. Ann Thorac Surg. 1975;20: 468-85.

2. Lowe JE, Oldham HN Jr, Sabiston DC Jr. Surgical management of congenital coronary artery fistulas. Ann Surg. 1981;194:373-80.

3. Bjork G, Crafoord C. Arteriovenous aneurysm of the pulmonary artery simulating patent ductus arteriosus botalli. Thorax. 1947;2:65-90.

4. Sakakibara S, Yokoyama M, Takao A, Nogi M, Gomi H. Coronary arteriovenous fistula: nine operated cases. Am Heart J. 1966;72:307-14.

5. Nagato H, Yokota M, Sakamoto K, Kado M, Nishioka M, Fujimoto K, et al. The repair of congenital coronary artery fistula in the neonatal period. Kyobu Geka. 1999;52:975-8.

6. Greene CL, Friedman KG, Callahan R, Baird CW. Case report: hybrid approach to neonatal repair of large symptomatic congenital coronary artery fistula. J Thorac Cardiovasc Surg Tech. 2020;3:295-7. 